\title{
Prediction of Adsorptive Capacity of Various Agricultural Wastes in the Removal of Heavy Metals, Dyes, and Antibiotic in Wastewater Using ANN
}

\author{
Aileen D. Nieva, Rosette Eira E. Camus, Eric R. Halabasco, Bonifacio T. Doma, and Reuben James Q. \\ Buenafe
}

\begin{abstract}
Artificial Neural Network model was proposed for the prediction of the adsorptive capacity of various agricultural wastes in the removal of heavy metals, dyes, and antibiotic in water. A total amount of 103 data sets were obtained from different literature and was split into training $(\mathbf{7 0 \%})$, validation $(\mathbf{1 5 \%})$ and testing $(\mathbf{1 5 \%})$ data. After considering different architectures, an input layer that uses eight independent variables (molecular weight of the adsorbate, adsorbent, adsorbent pre-treatment preparation, average initial concentration of adsorbate in solution, mass of adsorbent, adsorbent dosage, $\mathrm{pH}$, and temperature), one hidden layer with 18 neurons and one neuron in the output layer was found to give the best result. The overall mean square error was 3487 , while the correlation coefficient for the test dataset is $\mathbf{0 . 9 1 8 9 8}$.
\end{abstract}

Index Terms-Adsorptive capacity, agricultural wastes, artificial neural network, correlation coefficient.

\section{INTRODUCTION}

Aquatic pollution is now an increasing global problem due to continuous discharge of various chemicals (i.e. synthetic dyes, heavy metals and antibiotics) from different industries [1], [2]. Different technologies and techniques such as ion exchange, supercritical fluid extraction, adsorption, flocculation, coagulation, chemical precipitation, floatation, reverse osmosis, filtration, electrodialysis, precipitation, advanced oxidative process followed by membrane bioreactors, microbial system and electrochemical processes have been applied to remove these contaminants and improve the quality of water in accordance with local and national regulations. Among these technologies, adsorption is found to be the most effective method for wastewater treatment because of its efficiency, simplicity, and cost-effectiveness [3]. In search of highly effective, eco-friendly and cost-effective adsorbents, studies proved that over a wide variety of adsorbents such as zeolites, activated carbon, resins, silicate materials, among others, agricultural wastes are the most sustainable means of treating various contaminants in industrial effluents due to its abundance, cost, and minimal pre-treatment.

The most important parameter in assessing an adsorption

Manuscript received October 14, 2019; revised December 13, 2019.

The authors are with the School of Chemical, Biological, and Materials Engineering and Sciences, Mapua University, Muralla St., Intramuros, Manila, 1002, Philippines (e-mail: adnieva@ mapua.edu.ph). process of a system is the adsorptive capacity of the adsorbent. This parameter is affected by different operating conditions such as $\mathrm{pH}$, initial sorbate concentrations, adsorbent dosages, temperature, and other physical and chemical properties of the adsorbents like composition, pore size, surface area, and cationic exchange capacity. To determine the optimum operating conditions, experimentations must be conducted that would entail time and cost [3]. This concern is addressed with the application of several computer simulations like artificial neural networks (ANNs) to do prediction of properties [4]. ANN is a mathematical model based on biological nervous processing that utilizes interconnected nodes or neurons to model a response variable using several predictors through pattern recognition and information storage [3], [5]. ANN studies of this nature were used to predict properties of materials such as tensile strength and density [6] and bending strength and hardness [7]; in forecasting drying processes [8], energy systems [9], atmospheric systems [10], photovoltaic systems [11], and cooling systems [12]. Recently, different studies have shown that ANN could also be applied in adsorption systems to predict the process, kinetics, or removal efficiency [11]. Most ANN applications are being applied in the prediction of removal efficiency of dyes using nanoparticles or activated carbon. There have been very limited reports on applications of ANN in adsorption of pollutants using agricultural wastes [3].

The objective of this study is to produce a holistic model for predicting the adsorption capacity $(\mathrm{mg} / \mathrm{g})$ of a number of dyes, heavy metals, and antibiotics onto various types of agricultural wastes using ANN. Specifically, it aims to identify the most appropriate architecture, training algorithm, and transfer function for the dataset. The input parameters considered are the molecular weight of adsorbate, the agricultural waste used as adsorbent, the methods of pre-treating the adsorbent, the average initial concentration of the adsorbate in the solution $(\mathrm{mg} / \mathrm{L})$, mass of adsorbent used $(\mathrm{g})$, adsorbent dosage $(\mathrm{g} / \mathrm{mL}), \mathrm{pH}$ of the solution, and the temperature $\left({ }^{\circ} \mathrm{C}\right)$.

\section{Methodology}

\section{A. Description of the Dataset}

The data set is comprised of 103 observations obtained from various literature (Table I) that is described by 10 features, 3 of which are factor variables (adsorbent, adsorbate, and preparation) while the rest is either numerical variables or integers. 
TABLE I: THE ARRANGEMENT OF CHANNELS

\begin{tabular}{|c|c|c|c|}
\hline Adsorbate & MW $a$ & Agricultural Waste & $\operatorname{Ref} b$ \\
\hline Chromium (III) & 51.9961 & Spent tea dust, Coffee dust, Orange peel, Rice husk, Yellow passion fruit shell & [13], [14] \\
\hline Chromium (VI) & 51.9961 & Groundnut husk & [15] \\
\hline Tetracycline & 444.435 & Macadamia nut shells, Rice husk ash, Wheat straws ash, Apricot Nut Shells & [16], [17] \\
\hline Methylene blue & 319.85 & $\begin{array}{l}\text { Passion fruit peel, Rice husk, Brazil nut shells, Coconut coir pith, Unwanted weed, Banana peel, Orange } \\
\text { peel, Ashoka leaf }\end{array}$ & $\begin{array}{l}{[18],[19],} \\
{[20]} \\
{[21],[22]}\end{array}$ \\
\hline Indigo carmine & 466.36 & Brazil nut shells & {$[20]$} \\
\hline Amido black 10B & 616.487 & Banana peel, Orange peel & {$[22]$} \\
\hline Methyl orange & 327.33 & Banana peel, Orange peel & {$[22]$} \\
\hline Methyl violet & 393.95 & Banana peel, Orange peel, Sunflower seed hull & {$[22]$} \\
\hline Rhodamine B & 479.02 & Banana peel, Orange peel & {$[22]$} \\
\hline Congo red & 696.665 & Banana peel, Orange peel, Ground nut shells, Eichornia & {$[22],[23]$} \\
\hline Brilliant Green & 482.6 & Ashoka leaf & {$[23]$} \\
\hline Malachite green & 364.9 & Ashoka leaf & {$[23]$} \\
\hline Rhodamine B & 479 & Ashoka leaf, Cypress cone chips & [23], [24] \\
\hline Methylene blue & 373.91 & Cypress cone chips, Coconut shell, Factory-rejected tea, Karanj fruit hulls & {$[24]$} \\
\hline Copper (II) & 63.546 & $\begin{array}{l}\text { Ponkan Mandarin peels, Bagasse fly ash, Barley straw ash, Sugarcane bagasse, Orange peel, Citrus } \\
\text { maxima peel, Passion fruit shell, Potato peel }\end{array}$ & $\begin{array}{l}{[25],[26],} \\
{[27],} \\
{[28]}\end{array}$ \\
\hline Nickel (II) & 58.6934 & $\begin{array}{l}\text { Ponkan Mandarin peels, Bagasse fly ash, Barley straw ash, Sugarcane bagasse, Citrus maxima peel, } \\
\text { Passion fruit shell }\end{array}$ & $\begin{array}{l}{[25],[26],} \\
{[27],} \\
{[28]}\end{array}$ \\
\hline Lead (II) & 207.2 & $\begin{array}{l}\text { Sugarcane bagasse, Yellow passion fruit shell, Citrus maxima peel, Orange peel, Passion fruit shell, Pine } \\
\text { cone, Banana peel }\end{array}$ & $\begin{array}{l}{[28],[29]} \\
{[30],[31]}\end{array}$ \\
\hline Chromium (VI) & 52.9961 & Melaleuca diosmifolialeaf & {$[32]$} \\
\hline $\begin{array}{l}\text { ranitidine } \\
\text { hydrochloride }\end{array}$ & 350.87 & Mung bean husk & {$[33]$} \\
\hline Reactive blue 19 & 626.54 & Pomegranate peel & [34] \\
\hline Norfloxacin & 319.331 & Albizia lebbeck seed pods & {$[35]$} \\
\hline Ciprofloxacin & 331.346 & Albizia lebbeck seed pods, Date palm leaflets & {$[35],[36]$} \\
\hline Amoxicillin & 365.4 & Guava Seed & {$[37]$} \\
\hline
\end{tabular}

${ }^{b}$ Ref $=$ References used

\section{B. Artificial Neural Network}

To establish the neural network model, several key parameters were determined such as hidden layer nodes, learning algorithm, and transfer functions. A backpropagation (BP) neural network was used which includes the input layer, the hidden layer, and the output layer. The input layer has eight neurons given that there are eight input variables (molecular weight of the adsorbate, adsorbent, adsorbent preparation, average initial concentration of adsorbate in solution, mass of adsorbent, adsorbent dosage, $\mathrm{pH}$, and temperature) and the output layer has one output variable which is the monolayer adsorptive capacity. The implementation of the modeling is conducted using the neural network toolbox in Matlab R2018b.

To determine the best number of hidden layer nodes, the formula below was used:

$$
\begin{gathered}
l=\sqrt{n+m}+a \\
l=2 n+1
\end{gathered}
$$

where is $l$ the number of hidden layer nodes, $n$ is the input neurons, $m$ is the output neurons and $a$ is the regulating constant. Thus, based on (2), the best number of hidden layer nodes for this model is 17 .

However, due to the complexity of network mapping and the uncertainty of the training process, the equations above may not always be true. Hidden layer nodes can still be best determined by experiments but (1) and (2) can be used as a basis for the starting point and be changed incrementally. Having the right number of hidden layer nodes is important as it affects the performance of the neural network. If the hidden layer node is too less, then the convergence rate of the whole network may be reduced. Conversely, if the hidden layer node is too much, then the network topology will be complicated, and the error may not be optimal .

There were three learning algorithms used in this paper: trainlm (Levenberg-Marquardt), trainbfg (BFGS Quasi-Newton) and traingd (gradient decent).

The number of hidden layer nodes were set to 18 to 24 in increments of two and the three transfer functions; hyperbolic tangent-sigmoid, log-sigmoid, and the linear transfer function were also used to determine the optimum prediction model based on the training result.

$70 \%$ of the input data was used for training, $15 \%$ was used for testing and the other $15 \%$ was used for validation. The performance of the algorithm was evaluated using mean-squared error (MSE) and the correlation coefficient (R). The combination with the least training error and the maximum correlation coefficient was selected as the optimal neural network model.

\section{RESULTS AND DISCUSSION}

The results of the training and modeling showed that the optimum results can be achieved when the trainlm algorithm is used with hyperbolic tangent-sigmoid transfer function in the hidden layer. It was found out that the most appropriate 
number of hidden layer neurons is 18. Table II below summarizes the best result per training algorithm used in this work.

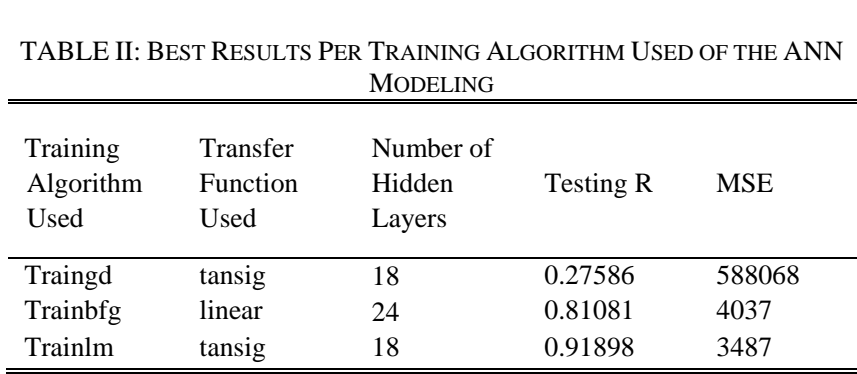

The results showed that the values of $\mathrm{R}$ for the training (0.93257) and validation (0.90978) datasets are relatively close and the correlation between the output and the target is very high. It can also be inferred from the result that the $\mathrm{R}$ value for the test dataset $(0.91898)$ is very close to the values of the training and validation datasets. A neural network could be more effective if a large amount of data is used [16]. Furthermore, it was found out that the best MSE is 3487 at the sixth epoch.

The neural architecture of the optimum model was 8-18-1 (input-hidden-output). Each of the eight input neurons receive one input ( $X i, i=1$ to 8$)$ and projects the result to each of the neurons in the hidden which eventually computes using the tansig transfer function and sends its result $(Y j, j=1$ to 18$)$ to the neuron in the output layer which finally produces the response of the network (Predicted Adsorptive capacity, $Z$ ). The output signal of each hidden neuron $(Y j)$ is calculated as:

$$
\begin{gathered}
Y_{j}=\operatorname{tansig}\left(\sum_{i=1}^{8} w_{i, j} X_{i}+b_{j}\right)= \\
\frac{2}{\left(1+\exp \left(-2\left(\sum_{i=1}^{8} w_{i, j} X_{i}+b_{j}\right)\right)\right)}-1
\end{gathered}
$$

while the output was computed as:

$$
\begin{gathered}
Z=\operatorname{tansig}\left(\sum_{i=1}^{18} w_{1, j} Y_{j}+b_{1}\right)= \\
\frac{2}{\left(1+\exp \left(-2\left(\sum_{i=1}^{18} w_{1, j} Y_{j}+b_{1}\right)\right)\right)}-1
\end{gathered}
$$

where $Z$ is the predicted adsorptive capacity, $Y_{j}$ are neurons of the hidden layer, $X_{i}$ are the input variables, $w_{i, j}$ and $w_{l, j}$ are the weights of the connections between the input and hidden neurons and between the hidden and output neuron, respectively and $b_{j}$ and $b_{1}$ are the biases on the hidden neurons and output neuron, respectively. The values for the weights and biases between the input and hidden layers are summarized in Table III while the weights and biases between the hidden and output layers are summarized in Table IV.

The comparison of the predicted data with that of the actual data is shown in Fig. 1 while the error for all data is shown in Fig. 2.

The results show good agreement between the actual and predicted adsorptive capacity. With the optimal model determined, it was also validated with different input variables as shown in Table $\mathrm{V}$.

TABLE III: WEIGHTS AND BIASES BETWEEN THE INPUT LAYER AND HIDDEN LAYER

\begin{tabular}{cccccccccc}
\hline \hline $\boldsymbol{j}$ & $\boldsymbol{w}_{j, 1}$ & $\boldsymbol{w}_{j, 2}$ & $\boldsymbol{w}_{j, 3}$ & $\boldsymbol{w}_{j, 4}$ & $\boldsymbol{w}_{j, 5}$ & $\boldsymbol{w}_{j, 6}$ & $\boldsymbol{w}_{j, 7}$ & $\boldsymbol{w}_{j, 8}$ & $\boldsymbol{b}_{j}$ \\
\hline 1 & 2.13 & -1.38 & 1.64 & 1.25 & -0.44 & -1.85 & -0.40 & 0.64 & -0.09 \\
2 & 0.40 & 0.32 & -0.47 & 1.01 & -0.44 & 1.26 & 0.08 & -0.62 & -1.34 \\
3 & -2.31 & 5.35 & -0.39 & -0.62 & 0.70 & -0.05 & 0.60 & -0.10 & 1.09 \\
4 & -0.89 & 1.82 & -1.24 & 0.80 & -2.92 & 1.17 & 2.32 & -0.48 & -1.34 \\
5 & 0.08 & 0.01 & 0.01 & 1.29 & -1.63 & -0.53 & -0.65 & 0.99 & 0.69 \\
6 & -0.71 & -0.09 & 0.51 & 1.03 & 1.12 & -0.30 & -0.17 & 0.97 & -2.04 \\
7 & 0.05 & 2.78 & 0.14 & -1.23 & -0.40 & -0.59 & -2.69 & -1.15 & -1.48 \\
8 & 0.68 & 1.40 & 0.71 & 0.65 & -0.06 & 0.39 & 0.29 & 1.96 & 1.16 \\
9 & -0.93 & 1.40 & 0.44 & -1.26 & -0.63 & 0.19 & -0.32 & -0.93 & -0.83 \\
10 & 0.65 & 0.05 & -0.82 & -0.43 & 0.30 & -2.00 & -1.34 & -2.71 & -2.23 \\
11 & 0.31 & -1.41 & -1.01 & -0.40 & -0.33 & 0.24 & -2.85 & -1.54 & -0.57 \\
12 & -0.72 & 0.64 & 1.96 & 0.91 & -0.77 & -0.55 & 0.07 & -0.31 & -0.66 \\
13 & -0.03 & 0.87 & 0.17 & 0.64 & 0.53 & 0.09 & -1.95 & 0.88 & -1.03 \\
14 & -0.16 & -2.47 & 0.22 & 1.27 & -1.27 & -0.16 & -0.57 & 0.40 & 2.62 \\
15 & -1.08 & -0.18 & 0.45 & -0.29 & 0.57 & -0.61 & -0.80 & 0.98 & 0.06 \\
16 & 1.45 & 0.77 & -0.49 & -0.29 & 0.02 & 0.05 & 0.51 & -0.17 & -0.64 \\
17 & 1.90 & -3.17 & -0.46 & -0.57 & 0.26 & -0.77 & -3.22 & 0.51 & -1.55 \\
18 & -2.65 & -0.79 & -1.00 & -0.71 & -1.31 & -0.70 & -1.26 & 0.01 & -0.36 \\
\hline \hline
\end{tabular}

TABLE IV: WEIGHTS AND BIASES BETWEEN THE HIDDEN LAYER AND OUTPUT LAYER

\begin{tabular}{cc}
\hline \hline Weight Number & Values \\
\hline$w_{l, 1}$ & 1.10 \\
$w_{1,2}$ & 0.53 \\
$w_{l, 3}$ & 1.30 \\
$w_{l, 4}$ & 0.89 \\
$w_{l, 5}$ & -0.48 \\
$w_{l, 6}$ & -1.45 \\
$w_{1,7}$ & -0.93 \\
$w_{l, 8}$ & 0.36 \\
$w_{1,9}$ & 0.67 \\
$w_{l, 10}$ & -0.28 \\
$w_{l, 11}$ & 0.50 \\
$w_{l, 12}$ & -0.64 \\
$w_{l, 13}$ & -0.40 \\
$w_{l, 14}$ & 0.60 \\
$w_{l, 15}$ & 0.22 \\
$w_{1,16}$ & 0.67 \\
$w_{l, 17}$ & -1.08 \\
$w_{l, 18}$ & 0.23 \\
$b_{1}$ & 0.48 \\
\hline \hline
\end{tabular}

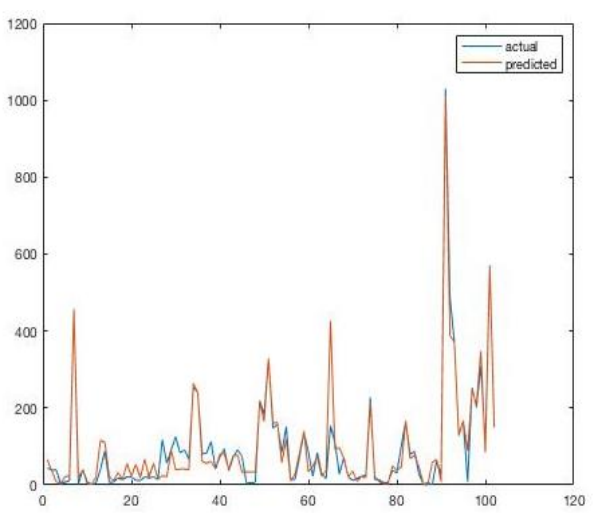

Fig. 1. Comparison of actual and predicted adsorptive capacity.

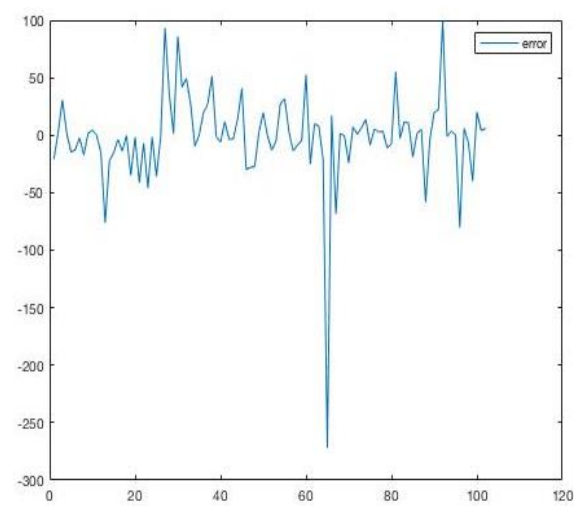

Fig. 2. Residual errors between the actual and predicted adsorptive capacity. 
TABLE V: RESUlTS OF THE TRAINING USING THE OPTIMAL MODEL WITH VARIATIONS IN INPUT PARAMETERS

\begin{tabular}{lll}
\hline \hline Architecture Input & Test R & MSE \\
\hline MW, AC, $\mathrm{C}_{0}$, Dose, Temp & 0.67369 & 14299 \\
MW, AC, $\mathrm{C}_{0}$, Mass, Dose, Temp & 0.90711 & 2017 \\
MW, AC, $\mathrm{C}_{0}$, Mass, Dose, pH, Temp & 0.9721 & 20307 \\
\hline \hline
\end{tabular}

It shows that the proposed ANN is sufficient and can be successfully used to predict the adsorption capacity of any contaminant adsorbed using any agricultural waste.

\section{CONCLUSION}

The adsorptive capacity of any pollutant i.e. heavy metals, dyes, and antibiotics in water onto any agricultural waste can be investigated through ANNs without doing costly and time-consuming experimentations. The prediced values of the adsorptive capacity of the different agricultural wastes were affected by the following parameters: 1) the molecular weight of adsorbate, 2) the type of agricultural waste used as adsorbent, 3) the methods of pre-treating the adsorbents, 4) the average initial concentration of the adsorbate in the solution $(\mathrm{mg} / \mathrm{L}), 5)$ mass of adsorbent used $(\mathrm{g}), 6)$ adsorbent dosage $(\mathrm{g} / \mathrm{mL}), 7) \mathrm{pH}$ of the solution and (8) the temperature $\left({ }^{\circ} \mathrm{C}\right)$. It was found out the most appropriate neural architecture was 8-18-1. The correlation coefficient and mean squared error using the optimum ANN model for the testing dataset is 0.91898 and 3487 , respectively. The results showed that the optimal model can be applied to predict the adsorptive capacity of various agricultural waste in adsorbing heavy metals, dyes, and antibiotics in response to any change in the input variables.

\section{CONFLICT OF INTEREST}

The authors declare no conflict of interest.

\section{AUTHOR CONTRIBUTIONS}

$A$ conducted the research and experiments, analyzed the data, and wrote the paper; $B, C$ and $E$ contributed to paper contents and edited and proofread the final paper, $D$ facilitated and conceptualized the whole research process and write-ups construction; all authors approved the final revision of the paper.

\section{REFERENCES}

[1] H. Chen, X. Qu, N. Liu, S. Wang, X. Chen, and S. Liu, "Study of the adsorption process of heavy metals cations on Kraft lignin," Chemical Engineering Research and Design, vol. 139, pp. 248-258, November 2018.

[2] J. Li, K. Zhang, and H. Zhang, "Adsorption of antibiotics on microplastics," Environmental Pollution, vol. 237, pp. 460-467, June 2018.

[3] A. M. Ghaedi and A. Vafaei, "Applications of artificial neural networks for adsorption removal of dyes from aqueous solution: A review," Advances in Colloid and Interface Science, vol. 245, pp. 20-39, July 2017.

[4] M. Y. Rafiq, G. Bugmann, and D. J. Easterbrook, "Neural network design for engineering applications," Computers \& Structures, vol. 79, pp. 1541-1552, July 2001.

[5] W. Sha and K. L. Edwards, "The use of artificial neural networks in materials science based research," Materials \& Design, vol. 28, pp. 1747-1752, January 2007.

[6] N. Altinkok and R. Koker, "Modelling of the prediction of tensile and density properties in particle reinforced metal matrix composites by using neural networks," Materials \& Design, vol. 27, pp. 625-631, January 2006.

[7] N. Altinkok and R. Koker, "Neural network approach to prediction of bending strength and hardening behaviour of particulate reinforced (Al-Si-Mg)-aluminium matrix composites," Materials \& Design, vol. 25, pp. 595-602, October 2004.

[8] T. Ttayagarajan, M. Ponnavaikko, J. Shanmugam, R. Panda, and P. Rao, "Artificial neural networks: principle and application to model based control of drying systems - A review," Drying Technology, vol. 16, pp. 931-966, 1998.

[9] S. A. Kalogirou, "Applications of artificial neural networks in energy systems," Energy Conversion and Management, vol. 40, pp. 1073-1087, July 1999.

[10] M. W. Gardner and S. Dorling, "Artificial neural networks (the multilayer perceptron) - A review of applications in the atmospheric sciences," Atmospheric Environment, vol. 32, pp. 2627-2636, 1998.

[11] A. Mellit, S. A. Kalogirou, L. Hontoria, and S. Shaari, "Artificial intelligence techniques for sizing photovoltaic systems: A review," Renewable and Sustainable Energy Reviews, vol. 13, pp. 406-419, 2009.

[12] D. B. Jani, M. Mishra, and P. K. Sahoo, "Application of artificial neural network for predicting performance of solid desiccant cooling systems - A review," Renewable and Sustainable Energy Reviews, vol. 80, pp. 352-366, December 2017.

[13] S. K. Prabhakaran, K. Vijayaraghavan, and R. Balasubramanian, "Removal of $\mathrm{Cr}$ (VI) ions by spent tea and coffee dusts: Reduction to $\mathrm{Cr}$ (III) and biosorption," Industrial \& Engineering Chemistry Research, vol. 48, pp. 2113-2117, 2009.

[14] S. Bellú, L. Sala, J. González, S. García, M. Frascaroli, P. Blanes et al., "Thermodynamic and dynamic of chromium biosorption by Pectic and lignocellulocic biowastes," Journal of Water Resource and Protection, vol. 2, p. 888, 2010.

[15] S. P. Dubey and K. Gopal, "Adsorption of chromium (VI) on low cost adsorbents derived from agricultural waste material: A comparative study," Journal of Hazardous Materials, vol. 145, pp. 465-470, 2007.

[16] A. C. Martins, O. Pezoti, A. L. Cazetta, K. C. Bedin, D. A. Yamazaki, G. F. Bandoch et al., "Removal of tetracycline by $\mathrm{NaOH}$-activated carbon produced from macadamia nut shells: Kinetic and equilibrium studies," Chemical Engineering Journal, vol. 260, pp. 291-299, 2015.

[17] Y. Chen, F. Wang, L. Duan, H. Yang, and J. Gao, "Tetracycline adsorption onto rice husk ash, an agricultural waste: Its kinetic and thermodynamic studies," Journal of Molecular Liquids, vol. 222, pp. 487-494, October 2016.

[18] F. A. Pavan, A. C. Mazzocato, and Y. Gushikem, "Removal of methylene blue dye from aqueous solutions by adsorption using yellow passion fruit peel as adsorbent," Bioresource Technology, vol. 99, pp. 3162-3165, 2008.

[19] V. Vadivelan and K. V. Kumar, "Equilibrium, kinetics, mechanism, and process design for the sorption of methylene blue onto rice husk," Journal of Colloid and Interface Science, vol. 286, pp. 90-100, 2005.

[20] S. M. Oliveira Brito, H. M. C. Andrade, L. F. Soares, and R. P. Azevedo, "Brazil nut shells as a new biosorbent to remove methylene blue and indigo carmine from aqueous solutions," Journal of Hazardous Materials, vol. 174, pp. 84-92, 2010.

[21] G. Annadurai, R.-S. Juang, and D.-J. Lee, "Use of cellulose-based wastes for adsorption of dyes from aqueous solutions," Journal of Hazardous Materials, vol. 92, pp. 263-274, 2002.

[22] B. Hameed, "Equilibrium and kinetic studies of methyl violet sorption by agricultural waste," Journal of hazardous materials, vol. 154, pp. 204-212, 2008.

[23] N. Gupta, A. K. Kushwaha, and M. Chattopadhyaya, "Adsorption studies of cationic dyes onto Ashoka (Saraca asoca) leaf powder," Journal of the Taiwan Institute of Chemical Engineers, vol. 43, pp. 604-613, 2012.

[24] M. Fernandez, G. Nunell, P. Bonelli, and A. Cukierman, "Batch and dynamic biosorption of basic dyes from binary solutions by alkaline-treated cypress cone chips," Bioresource Technology, vol. 106, pp. 55-62, 2012.

[25] F. A. Pavan, I. S. Lima, E. C. Lima, C. Airoldi, and Y. Gushikem, "Use of Ponkan mandarin peels as biosorbent for toxic metals uptake from aqueous solutions," Journal of Hazardous Materials, vol. 137, pp. 527-533, 2006.

[26] B. A. Shah, C. B. Mistry, and A. V. Shah, "Sequestration of Cu (II) and $\mathrm{Ni}$ (II) from wastewater by synthesized zeolitic materials: Equilibrium, kinetics and column dynamics," Chemical Engineering Journal, vol. 220, pp. 172-184, 2013.

[27] M. Arshadi, M. Amiri, and S. Mousavi, "Kinetic, equilibrium and thermodynamic investigations of $\mathrm{Ni}$ (II), Cd (II), Cu (II) and Co (II) adsorption on barley straw ash," Water Resources and Industry, vol. 6, pp. 1-17, 2014. 
[28] H.-P. Chao and C.-C. Chang, "Adsorption of copper (II), cadmium (II), nickel (II) and lead (II) from aqueous solution using biosorbents," Adsorption, vol. 18, pp. 395-401, 2012.

[29] A. Ofomaja and E. Naidoo, "Biosorption of lead (II) onto pine cone powder: studies on biosorption performance and process design to minimize biosorbent mass," Carbohydrate Polymers, vol. 82, pp. 1031-1042, 2010.

[30] A. A. Abdelhafez and J. Li, "Removal of $\mathrm{Pb}$ (II) from aqueous solution by using biochars derived from sugar cane bagasse and orange peel," Journal of the Taiwan Institute of Chemical Engineers, vol. 61, pp. 367-375, April 2016.

[31] J. Anwar, U. Shafique, Z. Waheed uz, M. Salman, A. Dar, and S. Anwar, "Removal of $\mathrm{Pb}$ (II) and $\mathrm{Cd}(\mathrm{II})$ from water by adsorption on peels of banana," Bioresource Technology, vol. 101, pp. 1752-1755, March 2010.

[32] S. Kuppusamy, P. Thavamani, M. Megharaj, K. Venkateswarlu, Y. B Lee, and R. Naidu, "Potential of Melaleuca diosmifolia leaf as a low-cost adsorbent for hexavalent chromium removal from contaminated water bodies," Process Safety and Environmental Protection, vol. 100, pp. 173-182, March 2016.

[33] S. Mondal, K. Sinha, K. Aikat, and G. Halder, "Adsorption thermodynamics and kinetics of ranitidine hydrochloride onto superheated steam activated carbon derived from mung bean husk," Journal of Environmental Chemical Engineering, vol. 3, pp. 187-195, March 2015.

[34] M. A. Ahmad, N. A. Ahmad Puad, and O. S. Bello, "Kinetic, equilibrium and thermodynamic studies of synthetic dye removal using pomegranate peel activated carbon prepared by microwave-induced KOH activation," Water Resources and Industry, vol. 6, pp. 18-35, August 2014.

[35] M. J. Ahmed and S. K. Theydan, "Fluoroquinolones antibiotics adsorption onto microporous activated carbon from lignocellulosic biomass by microwave pyrolysis," Journal of the Taiwan Institute of Chemical Engineers, vol. 45, pp. 219-226, January 2014.
[36] E.-S. I. El-Shafey, H. Al-Lawati, and A. S. Al-Sumri, "Ciprofloxacin adsorption from aqueous solution onto chemically prepared carbon from date palm leaflets," Journal of Environmental Sciences, vol. 24, pp. 1579-1586, September 2012.

[37] O. Pezoti, A. L. Cazetta, K. C. Bedin, L. S. Souza, A. C. Martins, T. L. Silva et al., "NaOH-activated carbon of high surface area produced from guava seeds as a high-efficiency adsorbent for amoxicillin removal: Kinetic, isotherm and thermodynamic studies," Chemical Engineering Journal, vol. 288, pp. 778-788, March 2016.

Copyright $\odot 2020$ by the authors. This is an open access article distributed under the Creative Commons Attribution License which permits unrestricted use, distribution, and reproduction in any medium, provided the original work is properly cited (CC BY 4.0).

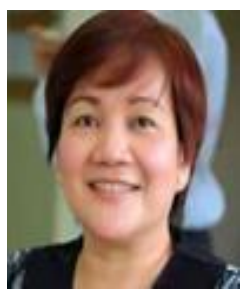

Aileen D. Nieva is the current director of the Mapua University Center for Continuing Education and Special Competencies. She graduated from Mapua University (formerly Mapua Institute of Technology) with a Ph.D. of chemical engineering.

Dr. Nieva has an immense amount of experience and training in technical consultancy and auditing jobs, specializing in waterworks and environmental sector. She is an environmental consultant, registered chemical engineer, certified QMS auditor, and lead auditor for ISO 9001:2008.

She is a professor at Mapua University since 1995 in environmental engineering, chemical engineering, differential equations, air pollution control, and specializing track such as Sustainable Engineering Technology. She received various awards such as Magna Cum Laude (Master of Science in Chemical Engineering), Most Outstanding Faculty Member 2002 (School of Chemical Engineering and Chemistry), and more. 